\title{
CARTOGRAFIAS DO SERTÃO rosiano
}

Evelina Hoisel

Desde que apareceu na cena cultural brasileira, a vasta produção literária de João Guimarães Rosa tem suscitado uma série de indagaçóes que perpassa diversos campos do conhecimento e contempla as interpretaçôes mais díspares e antagônicas. Isso se deve à própria configuração paradoxal desses textos, em que "tudo é e não é", pois "este mundo é muito misturado", como afirma o narrador protagonista de Grande sertão: veredas (1967), Riobaldo Tatarana.

Elegendo o sertão como cenário para as suas narrativas ficcionais, é com o texto monumental de Grande sertão: veredas que João Guimaráes Rosa traça uma geografia física, social e política do Brasil a partir do sertáo, périplo das aventuras do personagemnarrador, o jagunço Riobaldo.

Sob o aparente pretexto de informar a seu visitante, o senhor instruído e culto, sobre a geografia física e social da regiáo, Riobaldo começa a mapear a geografia do sertão com precisão e minúcia de quem efetivamente conhece o objeto de sua narração e se pốe também a delinear a sua cartografia interior, mapear as diversas zonas de sua subjetividade, buscando decifrar e interpretar os dados retidos na memória. No discurso de Grande sertão: veredas, sujeito e objeto se entrelaçam, pois é impossível para Riobaldo falar de sua travessia pelo sertão, estabelecer os limites físicos, geográficos e culturais da região, sem delimitar as zonas do seu eu. Temos assim, desde o início da epopeia, a possibilidade de traçar múltiplas cartografias, sejam elas reais, imaginárias, objetivas, subjetivas e afetivas. 
No Grande sertão, é a chegada do senhor-interlocutor que deflagra o diálogomonólogo que constitui a narrativa de Riobaldo. Todavia, é a figura de Diadorim que a sustenta e a fundamenta. Riobaldo não pode falar sobre o sertão sem atravessar o corpo polissêmico de Diadorim, pois seus rastros estáo inscritos na geografia física, social, cultural e mítica do sertão, recuperados pelas reminiscências de Riobaldo. A teia de acontecimentos da travessia do jagunço Riobaldo converge para a figura de Diadorim, e é a partir dela que ele terá que devassar um "mar de territórios, para sortimento de conferir o que existe" (ROSA, 1967, p. 25). Os rastros de Diadorim estáo no corpo físico de Riobaldo, na sua memória e na topografia do sertão - "Diadorim me pôs o rastro dele para sempre em todas essas quisquilhas da natureza" (ROSA, 1967, p. 25). A aprendizagem de Riobaldo consiste em um processo de interpretaçấo de si e do seu pertencimento ao bando de jagunços na travessia pelo sertão, e, nesse processo, ele está constantemente cartografando as diversas paisagens e convidando o leitor a se adentrar pelas suas trilhas para também mapear as suas veredas.

O conceito-metáfora de cartografia traduz uma apropriação, uma travessia literária por um território disciplinar um tanto incomum no panorama dos discursos sobre a literatura em sua relação com os demais saberes, ou seja, a geografia. Cartografar não significa a efetiva elaboração de cartas geográficas sobre os textos literários, embora elas também existam. Cartografar refere-se a uma configuração conceitual que pressupóe o estabelecimento de territorialidades literárias, comunidades imaginárias postas a dialogar e a se relacionarem, a partir de territorialidades linguísticas e culturais semelhantes ou divergentes. Cartografar pressupóe o delineamento de espacialidades, de fronteiras, a demarcação dos limites, reais ou virtuais, objetivos ou subjetivos, simbólicos ou alegóricos. Assim, falar de cartografias do sertão rosiano implica estabelecer limites, demarcar fronteiras, estabelecer percursos, aproximaçóes e distanciamentos entre os espaços físicos e geográficos do sertão, ou interpretar as marcas dos espaços subjetivos dos personagens conforme configurados no texto de João Guimarães Rosa, o Grande sertão: veredas.

O sertáo rosiano é diverso e variado, possibilitando o delineamento de uma multiplicidade de cartografias e mantendo sempre uma relaçáo ambivalente com a geografia física do sertão brasileiro. Se por um lado Rosa apoia-se na topografia do sertão, por outro lado inventa o espaço de acordo com seu projeto ficcional. O estabelecimento das cartografias do sertão rosiano ultrapassa o aspecto particularmente geográfico, transbordando para outras esferas, como a do mapeamento dos signos do amor de Riobaldo, a partir das relaçôes do jagunço-protagonista-narrador com as mulheres. Existe ainda uma geografia para se compreender a problemática do bem e do mal, vez que o mal se inscreve na prosa do mundo, constitui a topografia do sertão, possibilitando a marcação 
de outros desenhos cartográficos. Nesta leitura, interessa assinalar como em Grande sertão: veredas a constituição de uma cartografia do sertão tal como aparece nos mapas do Brasil comporta várias significaçóes simbólicas e várias possibilidades de leitura.

Alan Viggiano foi dos primeiros estudiosos a mapear o "itinerário de Riobaldo Tatarana" (título do seu livro, publicado em 1974), procurando demonstrar que, das quase 230 localidades citadas no romance - cidades, vilas, povoados, rios, córregos, serras, acidentes geográficos — , mais de 180 podem ser localizadas no mapa e são fruto de pesquisas que Guimarães Rosa realizou, estudando a região, percorrendo muitas léguas a cavalo, acompanhando boiadas com os vaqueiros Zito e Mariano. É esse o sertão físico, origem do escritor, no qual existem laços sanguíneos e consanguíneos, mantidos e preservados, mas também que serão vivenciados em outro nível da realidade delimitada simbolicamente pela linguagem.

O objetivo do estudo de Alan Viggiano é estabelecer o itinerário físico de Riobaldo Tatarana desde o momento em que ele se encontrou com Diadorim, e então começa a sua vida de jagunço, até o dia em que, no combate final com os judas, morre Diadorim, e ele, Riobaldo, deixa o cangaço. Entretanto, o próprio Viggiano salienta que é possível situar as localidades por onde andou Riobaldo antes de chegar ao Córrego do Batistério, que deságua no Rio das Velhas, à altura do município de Várzea da Palma, pouco abaixo da cidade de Pirapora. É nesse local que começa a sua vida de jagunço e também o drama amoroso que o acompanhará no cangaço.

Viggiano valoriza o que se pode considerar uma espécie de fidelidade de João Guimarães Rosa à cartografia do sertão brasileiro, conforme disseminado nos mapas convencionais, como se depreende da citação abaixo:

Levando-se em conta a imperfeição, ou melhor, o caráter incompleto dos trabalhos cartográficos - notoriamente justificáveis, de resto - e se se lembrar de que os lugares mudam constantemente de nome, circunstância contra a qual o próprio Riobaldo se insurge em um determinado trecho da narrativa, pode-se afirmar, sem receio de contestação, que Guimarães Rosa não inventou sequer um daqueles nomes. Todos foram tirados do seu caderninho de notas. (VIGGIANO, 1974.)

Em 2004, Willi Bolle, em sua abordagem grandesertão.br, procura definir o Grande sertão como um retrato do Brasil e como um romance de formaçáo, retomando o estudo de Alan Viggiano e reconhecendo o valor pioneiro dos mapas desenhados no Itinerário de Riobaldo Tatarana.

Contudo, denuncia e procura corrigir alguns equívocos do estudo de Viggiano, no sentido de não sobrevalorizar a geografia factual em detrimento do imaginário e da 
imprecisão estratégica da narrativa, que faz parte do projeto literário de João Guimarães Rosa. A partir do conceito de sertáo como "um labirinto, lugar por excelência do se perder e do errar", Willi Bolle afirma que, em Grande sertão: veredas, "apagam-se todas as referências, a cartografia chega ao limite e se desfaz" (BOLLE, 2004, p. 65), demonstrando como, sintomaticamente, no mapa de Viggiano não aparece nenhuma indicação topográfica em uma longa passagem do romance de quase cem páginas.

Willi Bolle chama atenção para o trecho em que Riobaldo atravessa o Ribeirão do Galho da Vida e chega ao Córrego Sucuriu e, nessa trajetória, Viggiano suprime a errância e deslocamento do jagunço para o sul, onde se localiza o povoado de Sucruiú, que, na expressão de Bolle, "não tem nada a ver com o referido córrego [ou seja, o Córrego do Sucuriu]" (BOLLE, 2004, p. 66). A passagem por Sucruiú é um dos episódios mais marcantes de Grande sertão: veredas e também uma cena de denúncia política e social dos ermos dos sertóes, do fundo sem fundo do sertão, e representa também a passagem pela peste, e essa experiência faz parte do périplo do protagonista-narrador.

Outro dado criticado por Willi Bolle na cartografia de Viggiano diz respeito ao fato de esse autor, no seu anseio de equacionar a paisagem ficcional à paisagem real, associar o Liso da Campina com o Liso do Sussuarão. Para Bolle, relacionar esses locais significa uma "tremenda redução" (BOLLE, 2004, p. 70), pois o Liso da Campina pode ser percorrido em poucas horas a pé, ao passo que o Sussuarão é, nas palavras de Riobaldo, "o raso pior havente", numa extensão de cinquenta léguas de fundo e quase trinta de largura.

Willi Bolle apoia-se ainda nos mapas de Marcelo de Almeida Toledo (1982), que ele considera mais bem realizados graficamente e mais exatos do que os de Viggiano, e nos mapas de Poty, que fizeram parte das primeiras ediçôes do romance. Nos de Poty, observa-se o uso livre dos dados geográficos, misturando elementos da cartografia convencional (rios, montanhas, cidades) com desenhos ilustrativos (vegetação, animais, homens, objetos), figuração de seres fabulosos (demônios, monstros), em um processo de desrealização da paisagem física.

Dos diversos mapas que constam de grandesertão.br, temos as seguintes descriçôes: Mapa 1 (BOLLE, 2004, p. 50-51), "Os sertóes do Brasil em Euclides da Cunha e em João Guimarães Rosa”. Mapa 3 (BOLLE, 2004, p. 60-61), retraça “o cenário de Grande sertão: veredas segundo Poty”, mostrando como as linhas de latitude e longitude sugerem a coexistência da geografia real com a imaginária. Mapa 4 (BOLLE, 2004, p. 68-69), "Introdução à topografia real e fictícia do Grande sertão: veredas", está basedo nos mapas de Alan Viggiano e Poty, para configurar as geografias reais e imaginárias desenhadas pelo autor de grandesertão.br. Nesse mapa, Bolle assinala como lugares-chave 
da história de Riobaldo, como as fazendas São Gregório, Santa Catarina, Sempre-Verde, o povoado do Sucruiú, as Veredas-Mortas e o Liso do Sussuarão, são inventados. Por outro lado, lugares como a Serra das Araras, a Serra e Mata da Jaíba, o Rio do Sono, o Paredão e a Lagoa Sussuarana ancoram a história na geografia real do sertão. Mapa 5 (BOLLE, 2004, p. 102-103), "Topografia da jagunçagem - In media res", Mapa 6 (BOLLE, 2004, p. 106-107), “Topografia da jagunçagem — Iniciação de Riobaldo”, e Mapa 7 (BOLLE, 2004, p. 114-115), “Topografia da jagunçagem — Chefia de Riobaldo" se atêm, conforme esclarece o autor, às referências geográficas reais.

Deve-se salientar que o livro de Willi Bolle resulta de longos anos de pesquisa. Nesse período, o autor percorreu diversas vezes o itinerário de Riobaldo, confrontando os mapas existentes e comparando a geografia literária com a geografia do sertão. Dessa comparação, pôde observar tanto as transformaçóes ecológicas ocorridas do tempo da publicação do Grande sertão para cá, constatando a existência de "uma paisagem tecnicizada e industrial” (BOLLE, 2004, p. 71), como também pôde compreender os mecanismos de funcionamento da escrita de Guimarães Rosa no sentido de superpor a geografia do sertão à geografia imaginária. É assim que Bolle interpreta os procedimentos ficcionais do Grande sertão:

O trabalho de campo nos leva, portanto, a verificar empiricamente quais são os principais procedimentos de uso ficcional da geografia por parte do romancista: as técnicas de fragmentação, desmontagem, deslocamento, condensação e remontagem. O narrador retira pedaços do sertão real e os recompóe livremente - de maneira análoga aos mapas mentais, que nascem da memória afetiva, de lembranças encobridoras, de pedaços de sonhos e fantasias, medos e desejos. (BOLLE, 2004, p. 71.)

Interessa essa colocação do autor de grandesertão.br, pois ela está confirmando o caráter paradoxal do sertão rosiano, exposto desde a primeira página do romance: o sertão é um espaço simultaneamente real e imaginário, factual e ficcional, objetivo e subjetivo e, de maneira mais ampla, concreto e metafísico. Desse modo, são múltiplas as cartografias que podem ser estabelecidas no itinerário de cada leitura, dependendo do recorte efetuado por cada leitor. Assim, pode-se entender a fala de Riobaldo no início do romance:

O senhor tolere, isto é o sertão. Uns querem que não seja: que situado sertão é por os campos-gerais a fora a dentro, eles dizem, fim de rumo, terras altas, demais do Urucuia. Toleima. Para os de Corinto e do Curvelo, então o aqui não é dito sertão? Ah, que tem maior! Lugar sertão se divulga: é onde os pastos carecem de fecho; onde um pode torar dez, quinze léguas, sem topar com casa de morador; e onde criminoso vive seu cristo-je- 
sus, arredado do arrocho de autoridade. O Urucuia vem dos montóes oestes. Mas, hoje, que na beira dele tudo dá - fazendóes de fazenda, almargem de vargens de bom render, as vazantes; culturas que vão de mata em mata; madeiras de grossura, até ainda virgens dessas lá há. O gerais corre em volta. Esses gerais são sem tamanho. Enfim, cada um o que quer aprova, o senhor sabe: pão ou pães é questão de opiniōes... O sertão está em toda parte. (ROSA, 1967, p. 9.)

Riobaldo estará durante o fluir da sua narrativa tentando organizar a paisagem brasileira, assumindo assim o papel de cartógrafo. Willi Bolle registra essa interação entre o narrador e o cartógrafo, afirmando que ela faz parte dos procedimentos de construção da paisagem, e compara os procedimentos utilizados pelo narrador de Grande sertão: veredas com aqueles encontrados em Os sertóes, de Euclides da Cunha, estabelecendo também as diferenças:

Euclides apresenta o sertão através de uma visão de cima. Seu livro inicia-se com um sobrevoo do Brasil... (BOLLE, 2004, p. 53.)

O olhar de Guimarães Rosa sobre o sertão é o exato oposto das vistas euclidianas do alto: é uma perspectiva rasteira. Enquanto o ensaísta-engenheiro sobrevoa o sertão como num aeroplano, o romancista caminha por ele como por uma estrada-texto. Ou então ele atravessa o sertão como um rio. (BOLLE, 2004, p. 76.)

Em termos gerais, pode-se adiantar que o narrador de Os sertóes tem uma autonomia menor em relação à cartografia que o de Grande sertão: veredas. (BOLLE, 2004, p. 58.)

A cartografia desenhada pelo grandesertão.br é norteada pela tese de seu autor, que pode ser sintetizada com as afirmaçôes encontradas nas páginas 122 e 125 do livro:

Assim, o projeto de Guimarães Rosa consiste em revelar o funcionamento do sistema real do poder no país, mostrando inclusive como determinadas utopias são manipuladas pela retórica dominante. (BOLLE, 2004, p. 122.)

Ao focalizar o sistema de jagunço, Guimarães Rosa não retrata um poder paralelo, mas o "poder". (BOLLE, 2004, p. 125.)

Além disso, as reflexôes de Bolle se orientam, como já foi salientado anteriormente, no sentido de afirmar Grande sertão como "o romance de formaçáo do Brasil" (que é o subtítulo do livro) e também como um retrato do Brasil, exibindo as questôes políticas e sociais do país - que são ainda bastante atuais, estão quotidianamente na nossa mídia - e expondo com exuberância e riqueza de detalhes a sua fauna e a sua flora, minuciosamente descritas pela fala de Riobaldo, esse narrador-cartógrafo. Como 
exemplo da importância do estudo da topografia do romance para se pensarem as questóes que fundamentam a tese do autor, retomo aqui o trecho em que Bolle, ao tratar da jagunçagem como "sistema retórico", demonstra que, em Grande sertão, a localização do sistema de jagunço "numa região limítrofe com os centros do poder, incluindo o território do Distrito Federal, confere ao texto o caráter de um retrato alegórico do Brasil” (BOLLE, 2004, p. 117). E, logo em seguida, ele se indaga e acrescenta:

O que significa essa encenação de bandos organizando o crime e exercendo o poder no planalto central? O sistema de jagunço, enquanto instituição situada ao mesmo tempo na esfera da lei e do crime, deixa de ser um fenômeno regional e datado, para tornar-se uma representação do funcionamento atual da estrutura do país. (BOLLE, 2004, p. 117.)

Diferentemente de Guimarães Rosa, o enfoque topográfico em outros autores, como Euclides da Cunha, ou em estudiosos como Rui Facó e Maria Isaura Pereira de Queiroz, mostra os jagunços e os cangaceiros como um fenômeno do Nordeste, não estando assim tão vinculados ao poder central como aparece em Guimarães Rosa. (BOLLE, 2004, p. 116.)

Ora, toda leitura é interessada, diz do sujeito que lê, mas ela é potencializada pela capacidade que tem o tecido textual de mobilizar várias interpretaçóes, por mais antagônicas que sejam. Willi Bolle demonstra na sua arrojada leitura do grandesertão.br como a falta de entendimento entre a classe dominante e as classes subalternas constitui um obstáculo para a emancipaçáo do país. Sua abordagem atravessa o território da geografia social, da história, da política e da estética. Por sua vez, o título do livro grandesertão. $b r$ faz alusão à comunicação contemporânea, remetendo à noção de hipertexto e internet, mapeando a rede de relaçóes entre Grande sertão: veredas e outros ensaios de interpretação do Brasil - Gilberto Freyre, Florestan Fernandes, Sérgio Buarque de Holanda, Caio Prado Júnior, Darcy Ribeiro. Com esse procedimento, Bolle está afirmando uma perspectiva teórico-crítica plenamente de acordo com determinados ingredientes textuais que ele encontra no romance, tendo como objetivo o mapeamento de questóes políticas e sociais, utilizando como ferramenta interpretativa os dados topográficos reais e imaginários - registrados na fala de Riobaldo. A leitura de Willi Bolle insere-se na vertente teórico-interpretativa da contemporaneidade, ao verificar as relaçóes texto-contexto a partir da rede de discursos que ele coloca em diálogo — os discursos da história, da sociologia, da antropologia etc. - para pensar um dado efetivo: Grande sertão como um retrato do Brasil.

Todavia, o sertão rosiano é, também, um sertão metafísico, espaço-tempo da 
intemporalidade e da atopia, da ausência de espaço, pois "o sertão está em toda parte", "o sertão é dentro da gente", é "o gerais." Esse aspecto está explicitado no conjunto da obra poética de João Guimarães Rosa, porém encontra-se claramente delineado como projeto literário no diálogo com o crítico e tradutor Günter Lorenz. Ao participar do Congresso de Escritores Latino-Americanos, em Gênova, em janeiro de 1965, dois anos antes da sua morte e quase dez anos depois da publicação de Grande sertão: veredas, Rosa deixa um de seus depoimentos mais longos em uma entrevista concedida a Günter Lorenz, que está publicada com o título de "Diálogo com Günter Lorenz" (COUTINHO, 1983, p. 62-97).

Conforme abordagem que realizei em Grande sertão: veredas: uma escritura biográfica (2006), no “Diálogo" o sertão mineiro é percebido através das diversas vertentes da escrita literária, principalmente Grande sertão: veredas, e é a essa obra que Guimarães recorre para cartografar o seu projeto sobre o sertão. Algumas metáforas utilizadas definem simultaneamente esse espaço como situado e dessituado geograficamente, de valor físico e metafísico. Uma metáfora que revela a mobilidade que têm os signos e as imagens de conotarem diversos significados está, por exemplo, na metáfora do vaqueiro, através da qual Guimarães Rosa se representa e constrói sua própria mitologia:

Isto pode surpreendê-lo, mas sou meio vaqueiro, e como você [isto é, o interlocutor G. Lorenz] também é algo parecido com isto, compreenderá certamente o que quero dizer. [...] Eu queria que o mundo fosse habitado apenas por vaqueiros. Então tudo andaria melhor. (COUTINHO, 1983, p. 67-68.)

O vaqueiro, como o sertanejo, é uma imagem que simboliza e desvela um modo de ser e de estar no sertão-mundo, no qual Guimarães se situa, situa seu interlocutor e todos aqueles personagens que constituem sua estirpe literária: Goethe, Dostoiévski, Tolstói, Flaubert, Balzac. O que define aquilo que Guimarães denomina de parentesco anímico é a relação que cada um desses escritores mantém com a sua linguagem - a sua língua - a partir de uma determinada forma de configurar a realidade. Depois de declarar a Günter Lorenz "levo o sertão dentro de mim e o mundo no qual vivo é também o sertão” (COUTINHO, 1983, p. 85), Rosa prossegue:

Goethe nasceu no sertão, assim como Dostoiévski, Tolstói, Flaubert, Balzac; ele era, como os outros que eu admiro, um moralista, um homem que vivia com a língua e pensava no infinito. Acho que Goethe foi, em resumo, o único grande poeta da literatura mundial que não escrevia para o dia, mas para o infinito. Era um sertanejo. (COUTINHO, 1983, p. 85.) 
E, logo depois, reconsidera essa afirmação do seguinte modo:

Portanto, torno a repetir: não do ponto de vista filológico e sim do metafísico, no sertão fala-se a língua de Goethe, Dostoiévski, Flaubert, porque o sertão é o terreno da eternidade, da solidão, onde o interior e o exterior já não podem ser separados. (COUTINHO, 1983, p. 86.)

De espaço geográfico e mundo físico, essa geografia não ficcional transforma-se em ficção, em realidade simbólica, alegórica e mitológica que não mais se desprega da não ficcional, e passa até a fornecer os parâmetros através dos quais ela pode ser pensada e experimentada, isto é, cartografada. Se a mineiridade está "inteiriça no romance", como afirma Letícia Malard em seu artigo "Minas Gerais em Guimarães Rosa” (MALARD, 1993, p. 36), ela aparece como pretexto para instalar essa outra dimensão táo perseguida por Rosa, tanto do ponto de vista da produçáo poética quanto do diálogo com Günter Lorenz: o sertão como não espaço e vivência do não circunstancial, (não) lugar do atemporal e do eterno. E é nessa acepção que Guimarães pode repetir no diálogo alguma coisa que aprendeu com seu personagem no Grande sertáo: veredas: “levo o sertão dentro de mim”, fazendo ecoar “o sertão é dentro da gente”, de Riobaldo Tatarana, o Urutu Branco.

O valor metafísico do sertão tem sido também objeto de abordagem da crítica rosiana. Heloisa Vilhena Araújo dedicou dois trabalhos ao tema, nos livros intitulados O roteiro de Deus (1996) e O espelho (1998). Francis Utéza elabora um estudo minucioso sobre a problemática da metafísica do Grande sertão, na obra Metafísica do grande sertão (1994). Sem negar a autenticidade da realidade brasileira, Utéza propóe-se a cartografar a paisagem que subjaz a essa geografia de superfície, desentranhando daí as grandes tradiçóes esotéricas do Oriente e do Ocidente que pautaram o comportamento das personagens na travessia pelo sertão, que ele traduz como Ser Tao - caminho da aprendizagem e de busca do conhecimento. Assim Utéza sintetiza e define o sertão metafísico:

Incomensurável, esse espaço contém tudo - gerais. Fora e dentro, margem esquerda e margem direita, singular e plural, montanha e vale, fértil e deserto, vazio e cheio, o sertão-gerais nada mais tem a ver com a geografia de Minas. [...] O termo sertão recobre o conceito metafísico da unidade caótica, plena de todos os possíveis, manifestados ou não: o Ser Tao engloba “o” Gerais. (UTÉZA, 1994, p. 66.)

Destaca-se essa afirmação como uma espécie de síntese das definições do sertão rosiano, porque expõe seu caráter de indecidível paradoxo. Há aqui uma tautologia, já 
que o paradoxo é por sua própria constituição um elemento indecidível, pois é regido pela combinação dos contrários e das aberrantes dicotomias. Todavia, essa colocação se justifica pela exuberância da construção linguística e literária de João Guimarães Rosa, que transgride os limites estabelecidos e regidos pela racionalidade que sustenta o pensamento e as açóes cotidianas, marcada pelos dualismos e pelas dicotomias.

O livro de Francis Utéza é de 1994 e adota uma perspectiva esotérica, mas para isso procura compreender o sertão, mapeando aquilo que ele denomina a "geografia do sagrado" (UTÉZA, 1994, p. 23). Ou seja, procura localizar as marcas das tradiçóes esotéricas do Oriente e do Ocidente inscritas na aventura de Riobaldo. Utéza, logo no início do seu livro - na parte II, "O pórtico do labirinto" - , analisa as ilustraçôes de Poty para a edição do romance, comparando o primeiro projeto do desenho das orelhas do livro com a versão definitiva, que aparecerá na segunda edição de Grande sertão: veredas. No desenho de Poty, feito por sugestão do próprio Guimarães Rosa, interessa a Utéza ler os dados esotéricos que se superpóem ao traçado da geografia de Minas, pois é nessa direção que se encaminha a sua abordagem, e, segundo ele, os desenhos de Poty são a primeira pista mais evidente para o esoterismo do romance. Cito uma passagem esclarecedora do seu interesse pela geografia e pelo estabelecimento de outras possibilidades cartográficas:

O filão metafísico que pudemos evidenciar se encontra submerso sob uma tal acumulação de dados geográficos, culturais, linguísticos e narrativos, que só um paciente trabalho de análise, fora do alcance do leitor não advertido, pode facultar a entrada nesse domínio. Solicitado, sobretudo, pelo superestrato folclórico e pelas premissas da narração de uma aventura heroica e de suspense, o leitor médio já tem suficientes dificuldades de reencontrar-se nele, e assim nem mesmo ser tentado a interessar-se por aquilo que lhe foi cuidadosamente escondido. (UTÉZA, 1994, p. 77.)

Logo no capítulo seguinte, intitulado "III. Realismo e transcendência”, Utéza observa que os trabalhos que procuraram seguir a trajetória dos jagunços através de mapas que o Exército fez do Centro-Oeste brasileiro provaram que a metafísica do Grande sertão "repousa sobre dados geográficos concretos" (UTÉZA, 1994, p. 79), estabelecendo ao mesmo tempo os limites desse tipo de pesquisa, já que "os signos do nada são perceptíveis até no meio ambiente: pode-se assimilá-lo ao Vão do Buraco, topônimo arquétipo do vazio". (UTÉZA, 1994, p. 83.)

As reflexôes de Utéza partem também do trabalho cartográfico de Alan Viggiano (1974), que ele considera "modesto", e do álbum de fotos que ilustra um conjunto de mapas detalhados, publicado por Marcelo de Almeida Toledo, no seu Grande sertão: veredas: as trilhas de amor e guerra de Riobaldo Tatarana (1982), afirmando que o maior 
número de localizações geográficas resulta desses cotejos. Entretanto, interessa a Francis Utéza desentranhar a realidade que subjaz a essa geografia aparente, corroborando uma declaração de Guimarães Rosa a F. Camacho, em uma entrevista: "quanto mais realista sou, você desconfie. Aí é que está o degrau para a ascensão, o trampolim para o salto” (UTÉZA, 1994, p. 82-83).

Nesse aspecto, muitos lugares do Grande sertão são evocados de modo que o leitor não possa relacioná-los a nenhum dado geográfico identificado nos mapas. Assim é o Liso do Sussuarão, as Veredas Mortas e muitos outros locais atravessados pelo narradorjagunço. Apoiando-se nas falas de Riobaldo que definem o Liso do Sussuarão como um lugar que "não concedia passagem a gente viva, era o raso pior havente, era um escampo dos infernos. [...] Que nem o Vão do Buraco [...] Esse Liso é o mais longe — pra lá, pra lá, nos ermos. Se emenda com si mesmo", e analisando as duas tentativas de travessia pelo Liso, onde ele aparece inicialmente como inferno e, posteriormente, como um oásis hospitaleiro, Utéza conclui da seguinte forma:

O Liso do Sussuarão não é apenas um deserto nos confins de Minas e Bahia, que audaciosos guerreiros tentaram em vão atravessar: é uma boca de sombra que devora suas vítimas, uma Vagina Dentada para a qual Medeiro Vaz arrasta seus jagunços sem que eles tenham regressado ao estado embrionário. Dessa garganta infernal ressurgem homens metafisicamente regenerados pela provação. (UTÉZA, 1994, p. 91.)

A abordagem metafísica de Utéza, baseando-se em símbolos da alquimia, do taoísmo e do zen, presentes na narrativa de Riobaldo, engloba a travessia das veredas a partir do nada - nonada, primeira palavra do discurso - até o infinito, último hieróglifo do texto. Nesse percurso de decifração desses signos, compreende a travessia de Riobaldo pelo sertão-mundo como um processo iniciático do Ser em direção ao Tao, ao conhecimento, percurso que já está contido na palavra sertão, pois o termo sertão "recobre o conceito metafísico de unidade caótica, plena de todos os possíveis, manifestados ou não: o Ser Tao engloba 'o' Gerais” (UTÉZA, 1994, p. 66).

Não é necessário continuar percorrendo a leitura de Utéza, pois ela é trazida aqui para atestar a capacidade que tem o texto rosiano de traçar múltiplas cartografias, até as mais excludentes. Se o sertão pode ser o retrato geográfico, social, histórico e político do Brasil, ele é também o Gerais, e "esses gerais são sem tamanho" e nada têm a ver com a geografia de Minas ou do Brasil. Apontam para uma caminhada ascensional, para uma transcendência, a travessia do homem para o infinito, como afirma o final da narrativa.

Através das palavras, Rosa constrói um mundo excessivo e excepcional, isto é, criador de exceçóes, em que a norma se espelha em seu contrário, e onde cada palavra 
fulgura como se fosse pronunciada pela primeira vez. Na sua concepção, explicitada também no diálogo com Günter Lorenz, a palavra é a única porta para o infinito, e o homem vive em constante travessia para o infinito. Esse é o término da narrativa do Grande sertão: veredas: a palavra Travessia, seguida pelo símbolo do infinito, a lemniscata. Dessa perspectiva, só é possível falar de cartografias do sertão rosiano, sem jamais se fixar em um mapa ou uma paisagem previamente estabelecida. Qualquer cartografia será móvel, instável, provisória e precária. Afinal, no sertão rosiano "tudo é e não é".

\section{$\operatorname{son}$}

\section{REFERÊNCIAS}

BOLLE, Willi. grandesertão.br: o romance de formação do Brasil. São Paulo: Duas Cidades; Editora 34, 2004. (Coleção Espírito Crítico).

HOISEL, Evelina. Grande sertão: veredas: uma escritura biográfica. Salvador: Academia de Letras da Bahia; Assembleia Legislativa do Estado da Bahia, 2006.

. Sobre cartografias literárias e culturais. In: MESSINA, Lea; BITENCOURT, Gilda N.; SCHIMIDT, Rita Terezinha. Geografias literárias e culturais: espaços e temporalidades. Porto Alegre: Editora da UFRGS, 2004, p. 149-156.

MALARD, Letícia. Minas Gerais em Guimarães Rosa. In: O espaço geográfico no romance brasileiro. Salvador: Fundação Casa de Jorge Amado, 1993, p. 33-50. (Casa de Palavras).

ROSA, João Guimarães. Grande sertão: veredas. 5. ed. Rio de Janeiro: José Olympio, 1967.

. Diálogo com Günter Lorenz. In: COUTINHO, Eduardo F. Guimarães Rosa. Rio de Janeiro: Civilização Brasileira; Brasília: INL, 1983. (Fortuna Crítica 6).

TOLEDO, Marcelo de Almeida. Grande sertão: veredas: as trilhas de amor e guerra de Riobaldo Tatarana. São Paulo: Massao Ohno, 1982.

UTÉZA, Francis. JGR: metafísica do grande sertão. Trad. José Carlos Garbulio. São Paulo: Edusp, 1994. VIGGIANO, Alan. Itinerário de Riobaldo Tatarana. Belo Horizonte: Comunicação; Brasília: INL, 1974.

\section{Resumo}

Estudo de Grande sertâo: veredas, considerando as diversas possibilidades de cartografar o sertão rosiano em seu sentido múltiplo e paradoxal. Traçar as cartografias do sertão rosiano implica em estabelecer limites, mapear fronteiras, definir percursos, aproximações e distanciamentos entre os espaços físicos e geográficos do sertáo, ou interpretar as marcas dos espaços subjetivos conforme configurados no texto de Joáo Guimarães Rosa. Considerando inicialmente as propostas de mapeamento do itinerário do personagem Riobaldo Tatarana, definidas como matrizes para estudos que se desenvolvem posteriormente, como a de Alan Viggiano e a de Potty, esta leitura se detém principalmente nas cartografias configuradas por Willi Bolle, em seu livro grandesertão.br. (2004) e 
por Francis Uteza, em JGR: Metafísica do Grande Sertão (1994). Procura-se explicitar como estas cartografias, embora resultando de perspectivas de abordagem diametralmente distintas e até opostas, traduzem os diversificados territórios geográficos e simbólicos que contornam os limites e deslimites do sertão rosiano, em que "tudo é e não é."

Palavras chave: Cartografias; Grande sertão: veredas; João Guimarães Rosa.

\section{Abstract}

A study of Grande sertâo: veredas, considering the several possibilities of drawing a cartography of the Rosean backlands in its multiple and paradoxical sense. Drawing the cartographies of the backlands of the Rosean backlands implies the setting of limits, border mappings, definition of paths, approximations and distancing between the physical and geographical spaces of the backlands, or interpreting the imprints of subjective sites as configured in João Guimarães Rosa's text. Considering, initially, the proposals of mapping the itinerary of the character RiobaldoTatarana defined as matrixes for the studies which are carried out subsequently, such as Alan Viggiano's and Potty's, this reading concentrates itself mainly in the cartographies configured by Willi Bolle in this book grandesertão.br. (2004), and Francis Uteza in JGR: Metafísica do Grande Sertão (1994). We attempt to explain how such cartographies, although resulted from different and even opposing perspectives, do translate the diversified geographic and symbolic territories which surround the limit and de-limits of the Rosean backlands, within the understanding of "everything is and is not".

Key words: Cartographies; Grande sertão: veredas; João Guimarães Rosa.

Evelina Hoisel é ensaísta, pesquisadora do CNPq, professora titular da Universidade Federal da Bahia, mestre em letras pela Pontifícia Universidade Católica do Rio de Janeiro e doutora em teoria da literatura e literatura comparada pela Universidade de São Paulo, já tendo publicado diversos livros, bem como artigos em jornais e revistas especializadas. Desde 2005 ocupa a Cadeira no 34 da ALB. 